\title{
OS ALUNOS DO INSTITUTO DE EDUCAÇÃO “FERNANDO COSTA" DA CIDADE DE PRESIDENTE PRUDENTE /SP: 1953-1963
}

\author{
Aline de Novaes Conceição \\ Universidade Estadual Paulista - UNESP, Programa de Pós-Graduação em Educação, Marília, SP. E-mail: \\ alinenovaesc@gmail.com. Agência de fomento: CNPq/Brasil.
}

\section{RESUMO}

Os Institutos de Educação eram instituições complexas cujo eixo central era a formação dos professores, tendo vários níveis de ensino. Na cidade de Presidente Prudente/SP, o Instituto de Educação era denominado de "Fernando Costa" e funcionou de 1953 a 1975. A partir disso, com o objetivo de reconstituir aspectos das vivências dos sujeitos, especificamente dos alunos do Instituto de Educação "Fernando Costa" entre 1953 a 1963, período em que se localizou fontes sobre o tema, realizou-se pesquisa com abordagem histórica, centrada em pesquisa documental e bibliográfica selecionando para análise atas e o livro de registros de penalidades dos alunos da instituição em questão. Constatou-se que se esperava que os alunos se submetessem ao diretor, aos professores e aos funcionários cumprindo as normas estabelecidas ou vigiadas por eles. Além disso, os alunos deveriam: solicitar autorização para saírem da instituição; comparecer em desfiles cívicos da cidade e permanecer em silêncio nas aulas.

Palavras-chave: Educação, História da Educação, História da Educação de Presidente Prudente/SP, Instituto de Educação, Alunos.

\section{THE STUDENTS OF THE "FERNANDO COSTA" INSTITUTE OF EDUCATION OF THE CITY OF PRUDENTE PRESIDENTE / SP: 1953-1963}

\begin{abstract}
The institutes of education and complex institutions whose axis was central, training of teachers, levels of education. In the city of Presidente Prudente/SP, the Institute of Education was denominated "Fernando Costa" and it worked from 1953 to 1975. From that, with the objective to reconstitute the experiences of the subjects, specifically of the students of the Institute of Education "Fernando Costa" Between 1953 and 1963, a period in which sources were located on the subject, a research with a historical focus was carried out, focused on documentary and bibliographical research selecting for analysis records and the book of records of penalties of the students of the institution Concerned. It was found that students were expected to submit to the principal, teachers and official officials as standards established or monitored by them. In addition, students should: request permission to leave the institution; At the civic parades of the city and remain silent in classes.
\end{abstract}

Keywords: Education, History of Education, History of Education of Presidente Prudente / SP, Institute of Education, Students. 


\section{INTRODUÇÃO}

Apresentam-se neste texto, parte dos resultados finais de pesquisa realizada no âmbito do Curso de Mestrado do Programa de Pós-Graduação em Educação da Faculdade de Filosofia e Ciências- FFC-, da Universidade Estadual Paulista -UNESP- "Júlio de Mesquita Filho", Campus de Marília/SP, sob a orientação do professor Dr. Macioniro Celeste Filho.

Os Institutos de Educação eram instituições complexas cujo eixo central era a formação dos professores, tendo vários níveis de ensino (Jardim da Infância, o Curso Primário, o Curso Ginasial, Colegial, Normal e os cursos de aperfeiçoamento para os membros do magistério) que possibilitavam vivências práticas para os professorandos e demais membros do magistério. $\mathrm{Na}$ cidade de Presidente Prudente/SP, o Instituto de Educação (IE) era denominado de "Fernando Costa" e funcionou de 1953 a $1975^{1}$.

No IE "Fernando Costa" havia o convívio de diversos sujeitos, dentre esses, havia, serventes, inspetores de alunos, escriturários, bibliotecário, secretários, diretores, professores e alunos estudando em diversos níveis de ensino. Magalhães (2004) relata que as Instituições Educativas apresentam uma estrutura física administrativa e sociocultural e o historiador precisa caracterizar atores e sujeitos e inferir a sua forma de participação.

A partir disso, o objetivo da pesquisa cujos resultados estão apresentados neste texto, consistiu em reconstituir aspectos das vivências dos sujeitos, especificamente dos alunos do Instituto de Educação "Fernando Costa", localizado na cidade de Presidente Prudente/SP, entre 1953 a 1963.

\section{METODOLOGIA}

Como procedimento metodológico da pesquisa, a fim de contemplar o objetivo, foi realizada pesquisa com abordagem histórica, centrada em pesquisa documental e bibliográfica, a partir dos procedimentos de localização, identificação, reunião, seleção e sistematização de fontes e bibliografia sobre o tema. Com esses procedimentos mencionados, foram elaborados dois instrumentos de pesquisas; um contendo referências de fontes localizadas no arquivo permanente do Instituto de Educação "Fernando Costa" e outro contendo referências de textos, sobre essa instituição, localizados nos números dos jornais impressos prudentinos.

A partir disso, para integrar o corpus documental da investigação, selecionaram-se fontes que pudessem tratar dos alunos do IE em questão, a saber: atas e o livro de registros de penalidades dos alunos do IE "Fernando Costa". Os registros sobre os alunos e as penalidades localizados no arquivo permanente da intuição abrangem o ano 1953 a 1963 e o ano de 1976, ou seja, houveram os registros até o ano que antecede o golpe que decorreu a ditadura militar, não havendo registros de 1964 a 1975. Para este texto, considerou-se os registros que abrangiam o ano de funcionamento do IE "Fernando Costa".

Além disso, realizou-se pesquisa bibliográfica sobre o tema cultura, História da Educação, arquivos e punições sofridas por alunos. A análise das fontes foi realizada concomitantemente com a análise bibliográfica sobre o tema, considerando a História Cultural, compreendendo a importância de pesquisar os cotidianos das instituições escolares a partir da utilização de diversas fontes e utilizando-se da

[...] cultura, enquanto construção social, como um conjunto de significados partilhados e construídos pelos homens para explicar o mundo a partir da análise de fontes variadas, representações, simbolismos, mentalidades, práticas, atribuindo assim sentido à realidade de uma determinada comunidade historicamente datada e localizada. (DINIZ, 2012, p. 18).

Nas pesquisas relacionadas com a História da Educação, é importante compreender que a “[...] incompreensão do presente nasce fatalmente da ignorância do passado." (BLOCH, 2001, p.

\footnotetext{
${ }^{1}$ Apesar de serem instalados em anos diversos, todos os Institutos de Educação do estado de São Paulo funcionaram até 1975. 
65). Assim, se torna pertinente e relevante conhecer o passado, para compreender o presente e buscar um futuro que se almeja.

\section{RESULTADOS}

No Instituto de Educação "Fernando Costa", os alunos eram punidos, as punições buscavam transformar os comportamentos indesejados dos alunos em comportamentos desejados, pois os alunos eram punidos por situações tidas como desvio do comportamento que atrapalhava o trabalho da instituição.

As punições sofridas pelos alunos do IE "Fernando Costa" consistiam em: repreensão verbal, repreensão escrita, suspensão de até oito dias, transferência compulsória, exclusão definitiva da escola e perda do ano letivo (IE ata, 1959-1966). No Quadro 1 abaixo, há o registro de 177 punições sofridas pelos alunos ${ }^{2}$ do IE "Fernando Costa":

Quadro 1. Punições sofridas pelos alunos do IE "Fernando Costa"

\begin{tabular}{|c|c|c|}
\hline TIPOS DE PUNIÇÕES & ANOS & $\begin{array}{l}\text { QUANTIDADE DE } \\
\text { CASOS }\end{array}$ \\
\hline \multirow{12}{*}{ Advertências ou repreensões } & 1953 & 4 \\
\hline & 1954 & 9 \\
\hline & 1955 & 3 \\
\hline & 1956 & 6 \\
\hline & 1957 & 8 \\
\hline & 1958 & 20 \\
\hline & 1959 & 16 \\
\hline & 1960 & 15 \\
\hline & 1961 & 13 \\
\hline & 1962 & 2 \\
\hline & 1963 & 11 \\
\hline & \multicolumn{2}{|c|}{ Total 107} \\
\hline \multirow{12}{*}{ Suspensões } & 1953 & 4 \\
\hline & 1954 & 1 \\
\hline & 1955 & 3 \\
\hline & 1956 & 3 \\
\hline & 1957 & 8 \\
\hline & 1958 & 7 \\
\hline & 1959 & 9 \\
\hline & 1960 & 4 \\
\hline & 1961 & 7 \\
\hline & 1962 & 7 \\
\hline & 1963 & 14 \\
\hline & \multicolumn{2}{|c|}{ Total 67} \\
\hline Perda do ano & 1960 & 1 \\
\hline Impossibilitados de realizarem a matrícula & 1961 & 1 \\
\hline Expulsão & 1963 & 1 \\
\hline Total de punições & \multicolumn{2}{|c|}{177} \\
\hline
\end{tabular}

Fonte: Registro de penalidades (IE, registro de penalidades, 1953-1976).

\footnotetext{
${ }^{2}$ Informa-se que na fonte localizada, apenas, esporadicamente, havia o curso que o aluno frequentava o que não possibilitou a inclusão dessa informação no Quadro 1.
} 
Comumente, os alunos ao serem repreendidos ou advertidos, eram informados de que na próxima vez que tivessem uma atitude similar seriam suspensos. Constatou-se que, inicialmente, como punições os alunos eram advertidos ou repreendidos, após, eram suspensos e, posteriormente, perdiam o ano ou eram transferidos ou expulsos.

No ano de 1958, foi o ano em que houve mais advertências ou repreensões aos alunos do IE "Fernando Costa" e no ano de 1959 foi o ano em que houve menos. Dentre as advertências sofridas pelos alunos do IE "Fernando Costa" destaca-se um caso em que por indisciplina "generalizada", as alunas do colegial tiveram que entregar uma caixa de giz para sanar a falta de material para a escola (IE, registro de penalidades, 1953-1976). Abaixo, no gráfico 1, há os cinco motivos mais recorrentes de advertências ou repreensões sofridas pelos alunos:

Gráfico 1. Motivos mais recorrentes de advertências ou repreensões sofridas pelos alunos do Instituto de Educação "Fernando Costa"

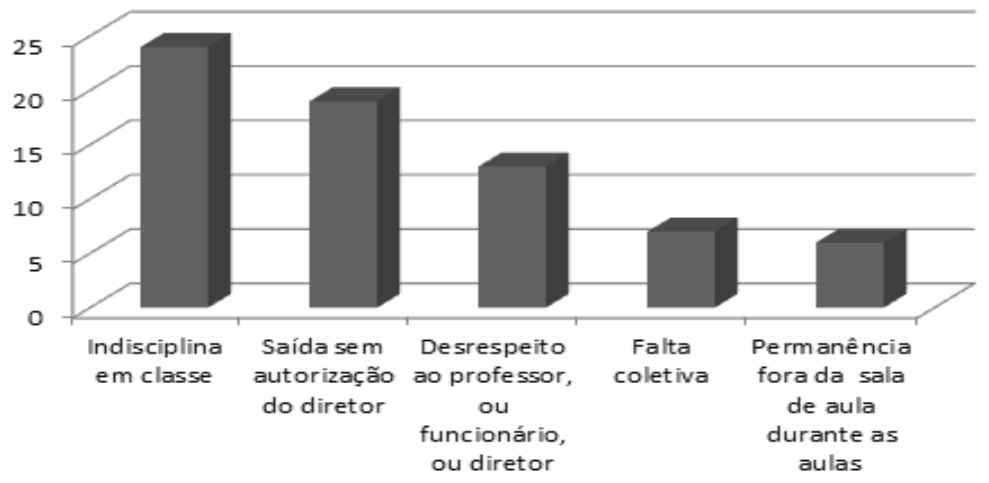

Fonte: Elaboração própria utilizando como fonte o Registro de penalidades (REGISTRO..., 1953).

De acordo com o Gráfico 1, acima, é possível constatar que os motivos mais recorrentes de advertências ou repreensões sofridas pelos alunos do IE "Fernando Costa", consistiram em: "Indisciplina em classe" (24), "Saída do estabelecimento sem autorização do diretor" (19) e "Desrespeito ao professor, ou funcionário, ou diretor" (13). No Gráfico 2 abaixo, inseriram-se os cinco motivos mais recorrentes de suspensões sofridas pelos alunos.

Gráfico 2. Motivos mais recorrentes de suspensões sofridas pelos alunos do IE "Fernando Costa"

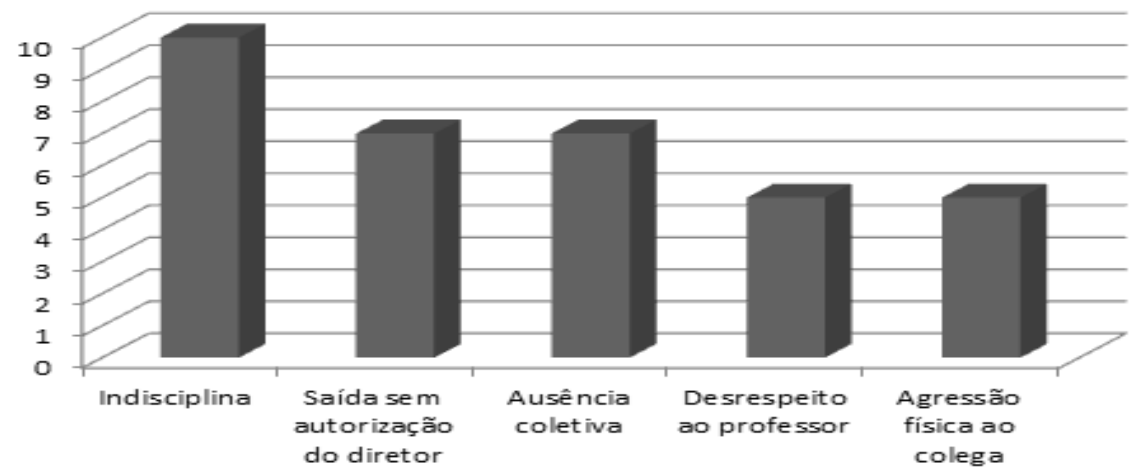

Fonte: Elaboração própria utilizando como fonte o Registro de penalidades (REGISTRO..., 1953).

Os motivos mais recorrentes de suspensões sofridas pelos alunos do IE "Fernando Costa", consistiram em: "Indisciplina" (10), "Saída do estabelecimento sem autorização do diretor" (7) e "ausência coletiva" (7). Constata-se que os dois motivos mais recorrentes de suspensões são idênticos aos motivos de advertências ou repreensões.

Em relação a indisciplina, é possível constatar que em 1965, após ser relatado sobre mais um caso de indisciplina de um dos alunos do IE "Fernando Costa", o diretor dessa instituição 
sugeriu a criação da Associação de Pais e Mestres com a finalidade de esclarecer aos pais sobre as atividades dos seus filhos na escola (IE ata, 1959-1966). Em relação a "ausência coletiva", destacase que a turma que faltava às aulas recebia suspensões coletivas com rodízios de dias em que os alunos seriam suspensos.

Os alunos que não cumpriam as ordens das instituições eram ameaçados, afirmando que poderiam efetuar a matrícula no próximo ano, ou poderiam permanecer no mesmo ano escolar, como em um caso em que um aluno desrespeitou a direção e por isso não poderia efetuar a matrícula para o ano seguinte, devendo permanecer no mesmo ano escolar.

Acima da punição de suspensão estava a punição de transferência compulsória e exclusão definitiva da escola, localizou-se um caso no IE "Fernando Costa" em que o aluno teve "Expulsão com expedição de transferência compulsória. [por] Indisciplina, desacato a autoridades escolares encarregados da administração, ameaças e agressão [...]" (IE, registro de penalidades, 1953-1976, p. 112) e localizou-se um aviso de 1966, em que o diretor solicitou que todos os professores avisassem os alunos da possibilidade de transferência compulsória por "cola" ${ }^{3}$ (IE, atas, 19591966).

No IE "Fernando Costa" os pais interferiam nas punições que os alunos sofriam e assim as amenizavam como no caso em que um aluno foi suspenso e advertido por desrespeitar o professor. Entretanto o pai interveio, mencionando que esse fato não ocorreria mais e a punição para o aluno foi transformada em advertência.

Em outro caso, o aluno recebeu suspensão de oito dias e caso o pai fosse até a escola explicar, a pena seria reduzida para três dias. Em outro caso o aluno seria transferido e, então, o responsável desse aluno mencionou que o aluno estava passando por tratamento médico e a "[...] a transferência para outra instituição implicaria na perda do ano letivo [...]" (IE, registro de penalidades, 1953-1976, p. 80). Com isso, a transferência desse aluno foi decidida que ocorreria no próximo ano letivo e naquele ano o aluno seria suspenso.

\section{DISCUSSÃO}

Cabral (2002, p. 100), ao tratar das punições na instituição que pesquisou também menciona que estavam relacionadas a "[...] situações colocadas como problemas para o andamento dos trabalhos [...]". A autora afirma que a "[...] punição é utilizada como um corretivo para a mudança de comportamento dos alunos, simboliza o resultado de práticas que são consideradas impróprias para o espaço." (CABRAL, 2002, p. 104).

Assim, ao relacionar com o IE "Fernando Costa", é possível constatar que as punições evidenciam quais as normas que não estavam sendo cumpridas internamente nessa instituição, pois o "[...] desvio e a marginalidade dizem muito sobre a norma e sobre o poder político, e cada tipo de delito reflete um aspecto da sociedade." (FARGE, 2009, p. 33).

Segundo informações contidas na fonte Registro de penalidades, as suspensões do IE pesquisado, as punições ocorriam como medida "preventiva e educacional" (IE, registro de penalidades, 1953-1976, p. 51). O IE "Fernando Costa" era uma instituição de prestígio social e mesmo assim era composta de resistências e transgressões às normas por parte dos alunos o que geravam punições a fim de que comportamentos tidos como inadequados fossem transformados.

Cabral (2002, p. 107) afirma que as "[...] punições revelam qual o papel da escola na intervenção da correção dos comportamentos indesejáveis, na medida em que estabelece regras, mediante vários mecanismos de coerção.".

Dentre essas punições, no IE "Fernando Costa" a mais recorrente ocorreu por motivo de indisciplina, é importante considerar que "[...] a indisciplina se constrói em oposição a disciplina escolar, que tem como finalidade garantir o bom funcionamento a instituição [...]" (CABRAL, 2002, p. 97).

${ }^{3}$ Ato de copiar respostas para realizar as atividades solicitadas pelo professor. 
Em relação a essa ação verifica-se que no IE em questão foi criada uma comissão de quatro alunos que se comprometia "[...] a levar a Direção do estabelecimento o nome dos alunos transgressores da disciplina, para fim de serem aplicadas as penalidades regimentais." (IE, registro de penalidades, 1953-1976, p. 20). Dessa forma, no IE "Fernando Costa", os alunos também eram vigiados pelos próprios colegas e caso tivessem comportamentos indesejados eram punidos.

O segundo motivo mais recorrente de punições ocorreu por saída dos alunos do estabelecimento sem autorização, é possível que isso tenha ocorrido devido ao funcionamento do prédio da instituição, pois em 1965, o Inspetor Escolar Estadual, solicitou o fechamento da "[...] saída de fundos do Colégio pelo Clube de Química evitando assim que os alunos abandonem a Escola por aquela via [...]" (IE, têrmo de visita do inspetor estadual, 1960-1983).

\section{CONSIDERAÇÕES FINAIS}

Segundo Souza (1998, p. 138) a "[...] escola transmissora da ciência e dos conhecimentos úteis é também a responsável pela formação de bons hábitos, bons costumes, bons comportamentos.".

Para o historiador francês Dominique Julia (2001, p. 9) na instituição escolar, há uma cultura escolar que é um "[...] conjunto de normas que definem conhecimentos a ensinar e condutas a inculcar, e um conjunto de práticas que permitem a transmissão desses conhecimentos e a incorporação desses comportamentos. ".

No IE "Fernando Costa" dentre as "condutas a inculcar" nos alunos, analisando os motivos das advertências, repreensões ou suspensões é possível constatar que se esperava que os alunos do IE "Fernando Costa" se submetessem ao diretor, aos professores e aos funcionários cumprindo as normas estabelecidas ou vigiadas por eles. Além disso, os alunos deveriam solicitar autorização para saírem da instituição, deveriam comparecer em desfiles cívicos da cidade e deveriam permanecer em silêncio durante as aulas.

Dentre as práticas realizadas para que ocorresse a incorporação desses comportamentos, no IE "Fernando Costa", estavam as advertências ou repreensões, as suspensões, as perdas do ano e as transferências ou expulsões. Os alunos que tinham comportamentos indesejados sofriam punições com o fim de que os seus comportamentos fossem transformados em comportamentos desejados, tidos como adequados para o bom funcionamento da instituição.

\section{REFERÊNCIAS}

BLOCH, Marc Leopold Benjamin. Apologia da história ou o ofício de historiador. Rio de Janeiro: Jorge Zahar, 2001.

CABRAL, Maria Aparecida da Silva. A invenção do aluno: a implantação do Primeiro Gymnasio da Capital, São Paulo (1894-1917). 2002. 204 f. Dissertação (Mestrado em Educação)-Pontifícia Universidade Católica de São Paulo, São Paulo, 2002.

DINIZ, Carlos Alberto. A educação secundária no interior paulista: estudo histórico sobre o Ginásio estadual de Matão (1940-1965). 2012. 117 f. Dissertação (Mestrado em Educação)Universidade Estadual Paulista, Araraquara, 2012.

FARGE, Arlette. 0 sabor do arquivo. São Paulo: Edusp, 2009.

INSTITUTO DE EDUCAÇÃO “FERNANDO COSTA". Registro de penalidades. [Presidente Prudente], 1953-1976. $119 p$ 
INSTITUTO DE EDUCAÇÃO “FERNANDO COSTA". Livro de ata das reuniões "conselho de professores" (congregação). Presidente Prudente, 30 abr. 1959-1966. 100p.

INSTITUTO DE EDUCAÇÃO "FERNANDO COSTA". Têrmo de visita do inspetor estadual. [Presidente Prudente], 14 mar. 1960-1983. 100p

JULIA, Dominique. A cultura escolar como objeto histórico. Revista Brasileira de História da Educação, Campinas, n. 1, p. 9-43, jan./jun. 2001.

MAGALHÃES, Justino Pereira de. Tecendo nexos: história das instituições educativas. Bragança Paulista: Editora Universitária São Francisco, 2004.

NÓVOA, António. Apresentação. In: CAMBI, Franco. História da pedagogia. São Paulo: Editora da Universidade Estadual Paulista, 1999. p. 11-15.

RIBEIRO, Arilda Ines Miranda. Subsídios para a História da Educação em Presidente Prudente: as primeiras instituições escolares. São Paulo: Clíper, 1999.

SOUZA, Rosa Fátima de. Templos de civilização: a implantação da Escola Primária graduada no Estado de São Paulo (1890-1910). São Paulo: Fundação Editora da UNESP, 1998. 